\title{
Electrocatalytic Performance and Stability of Nanostructured Fe-Ni Pyrite-Type Diphosphide Catalyst Supported on Carbon Paper
}

\author{
José Diogo Costa, ${ }^{\dagger}$ José Luis Lado, ${ }^{\dagger}$ Enrique Carbó-Argibay, ${ }^{\dagger}$ Elvira Paz, ${ }^{\dagger}$ Juan Gallo, $^{\dagger}$ \\ M. Fátima Cerqueira, ${ }^{\star}$ Carlos Rodríguez-Abreu, ${ }^{\dagger}$ Kirill Kovnir, ${ }^{\S}$ and Yury V. \\ Kolen'ko* ${ }^{\dagger}$ \\ ${ }^{\dagger}$ International Iberian Nanotechnology Laboratory, Braga 4715-330, Portugal \\ Center of Physics, University of Minho, Braga 4710-057, Portugal \\ ${ }^{\S}$ Department of Chemistry, University of California, Davis, Davis CA 95616, USA
}

\begin{abstract}
A simple and effective method to prepare an active and stable nanostructured working electrode for electrochemical water splitting is described. Specifically, mixed $\mathrm{Fe}-\mathrm{Ni}$ diphosphide was prepared by sputtering a 200-nm-thick layer of Permalloy onto carbon paper gas diffusion layer followed by gas transport phosphorization reaction. The mass density of the resultant diphosphide phase was established to be $\approx 1.1$ $\mathrm{mg} / \mathrm{cm}^{2}$. Energy-dispersive X-ray microanalysis shows that the actual elemental composition of the resultant ternary electrocatalyst is approximately $\mathrm{Fe}_{0.2} \mathrm{Ni}_{0.8} \mathrm{P}_{2}$, while the powder X-ray diffraction analysis confirms that the electrocatalyst crystallizes in $\mathrm{NiP}_{2}$ cubic pyrite-like structure. As a cathode for hydrogen evolution reaction (HER) in acidic and alkaline electrolytes, this earth-abundant electrode has exchange current densities of $6.84 \times 10^{-3}$ and $3.16 \times 10^{-3} \mathrm{~mA} / \mathrm{cm}^{2}$ and Tafel slopes of 55.3 and $72.2 \mathrm{mV} / \mathrm{dec}$, respectively. As an anode for oxygen evolution reaction (OER) in alkaline electrolyte, the electrode shows an exchange current density of $2.88 \times 10^{-4} \mathrm{~mA} / \mathrm{cm}^{2}$ and Tafel slope of $49.3 \mathrm{mV} / \mathrm{dec}$. The observed high activity of the electrode correlates well with its electronic structure, which was assessed by density functional theory (DFT) calculations. The stability of $\mathrm{Fe}_{0.2} \mathrm{Ni}_{0.8} \mathrm{P}_{2}$ electrocatalyst in HER and OER was evaluated by means of accelerated degradation test and chronopotentiometry. The results of these experiments elucidate partial dissolution and entire chemical transformation of $\mathrm{Fe}_{0.2} \mathrm{Ni}_{0.8} \mathrm{P}_{2}$ as the main mechanisms of the electrode degradation during HER and OER, respectively. Overall, our findings could facilitate the composition-based design of active, stable, and durable phosphide electrodes for electrochemical water splitting.
\end{abstract}

\section{INTRODUCTION}

$\mathrm{H}_{2}$ plays an important role in clean energy technology, complementing intermittent solar/wind power. ${ }^{1}$ Remarkably, lightweight $\mathrm{H}_{2}$ has the highest specific energy of any known non-nuclear fuel, and it can be used for both energy generation and storage purposes. More importantly, $\mathrm{H}_{2}$ is an environmentally friendly fuel, since only energy and water are the end products of the reaction between $\mathrm{H}_{2}$ and $\mathrm{O}_{2}$, giving rise to the emerging fuel cell technologies and devices.

Notably, there are no natural sources of $\mathrm{H}_{2}$ gas on Earth, and therefore, large-scale production of $\mathrm{H}_{2}$ is always driven by energy input. For instance, more than $95 \%$ of $\mathrm{H}_{2}$ is currently produced through steam reforming reaction of water with natural gas/fossil fuel, typically over nickel catalyst at high temperatures $\left(\geq 700{ }^{\circ} \mathrm{C}\right) .^{2}$ The main drawbacks of steam reforming are the high energy and cost demands of the process, low purity of the resultant $\mathrm{H}_{2}$, and emissions of greenhouse gases.

An interesting alternative to steam reforming is offered by water electrolysis, wherein water is simply decomposed to $\mathrm{H}_{2}$ and $\mathrm{O}_{2}$ by applying a voltage bias. Although the era of water electrolysis began more than three centuries ago, the world-wide implementation of this technology is still limited to $\mathrm{H}_{2}$ production up to the megawatt range using alkaline electrolysis. This is mainly due to the fact that the water splitting reaction is a kinetically controlled process characterized by slow charge transfer and insufficient chemical reaction rates, and in reality, a significantly higher overpotential than the standard 
potential of the water electrolysis $\left(-1.23 \mathrm{~V}\right.$ at $\left.25^{\circ} \mathrm{C}\right)$ needs to be applied to drive the reaction. ${ }^{4}$ Therefore, electrocatalysts are used to facilitate water electrolysis by reducing the value of the applied overpotential to conduct cathodic hydrogen evolution reaction (HER) and anodic oxygen evolution reaction (OER), which are the key half reactions of electrochemical water splitting. ${ }^{4}$

The best performing and long lasting electrocatalysts for HER and OER are Pt and $\mathrm{IrO}_{2}$, respectively. ${ }^{5-6}$ Also, other platinum group metals (PGMs) and PGM-containing compounds show high electrocatalytic performance in water electrolysis. PGMs are, however, scarce in the earth's crust, and therefore, they are expansive materials with limited availability. Consequently, there is an important branch of electrochemical water splitting research dealing with the development of earth-abundant electrocatalysts for HER/OER based on $3 d$ transition metals (TMs), such as $\mathrm{Fe}, \mathrm{Co}, \mathrm{Ni}$, and $\mathrm{Cu}$. As a result of significant advances in the area over the last two decades, $\mathrm{Ni} / \mathrm{C}$ and mixed $\mathrm{Fe} / \mathrm{Co} / \mathrm{Ni}$ electrocatalysts are currently used in the state-of-the-art alkaline electrolyzers for HER and OER, respectively. ${ }^{7}$ Notably, the catalytic activity, stability and durability of the metallic TMs are quite low, but fortunately significant improvements can be made through the introduction of other nonmetal elements, such as B, C, N, P, O, and $\mathrm{S}^{8-11}$

To this end, we recently embarked on the synthesis and investigation of nickel phosphide Ni-P electrocatalysts using a commercially available $\mathrm{Ni}$ foam current collector as a precursor. We demonstrated that the resultant self-supported electrodes were highly active towards HER in terms of the onset potentials, exchange current densities, and Tafel slopes. ${ }^{12-14}$ As the mass loading of the nickel phosphide phase was quite high in these electrodes $\left(50-60 \mathrm{mg} / \mathrm{cm}^{2}\right)$, we hypothesized that the phosphide phase can be supported on a conductive carbon paper gas diffusion layer (GDL). In this way, one can reduce the electrocatalyst loading while providing high surface area, and thus preserving high electrocatalytic activity.

In the present work, we apply this methodology to synthesize a working electrode for electrochemical water splitting using magnetic Permalloy as a precursor. The resultant electrode $\mathrm{Fe}_{0.2} \mathrm{Ni}_{0.8} \mathrm{P}_{2} / \mathrm{C}$ paper GDL has a diphosphide phase mass density of only $\approx 1.1 \mathrm{mg} / \mathrm{cm}^{2}$. The electrode is studied in the HER/OER, and we address the activity of the diphosphide electrocatalyst by density functional theory (DFT) band structure calculations. Finally, our data uncover the degradation mechanism of $\mathrm{Fe}_{0.2} \mathrm{Ni}_{0.8} \mathrm{P}_{2} / \mathrm{C}$ paper GDL during HER/OER, as well suggest that exploiting chemical composition in combination with computational simulation and in situ characterization could yield active, stable, and durable phosphidebased electrodes.

\section{EXPERIMENTAL SECTION}

Reagents. Permalloy, $\mathrm{Fe}_{0.2} \mathrm{Ni}_{0.8}$, sputtering target $(99.95 \%$, Materion, $\varnothing=50.8 \mathrm{~mm}$, thickness $=3.175$ $\mathrm{mm}$ ), powdered red phosphorous (98.9\%, Alfa Aesar), sulfuric acid (95-98\%, Sigma-Aldrich), potassium hydroxide ( $\geq 85 \%$, Sigma-Aldrich), graphite rods $(99.995 \%$, Sigma-Aldrich), platinum wire $(99.9 \%$, Sigma-Aldrich), and carbon paper GDL (Toray Paper 120) were used as received. Ultrapure water (18.2 $\mathrm{M} \Omega / \mathrm{cm}^{2}$ ) was produced using a Milli-Q Advantage A10 system (Millipore).

Preparation of electrode. First, a 200-nm-thick film of Permalloy was sputtered onto both sides of a C paper GDL specimen $(10 \mathrm{~cm} \times 10 \mathrm{~cm})$ using a multi-target ultra-high vacuum sputtering system (Kenosistec), operated under a base pressure of $5 \times 10^{-8}$ Torr. The depositions were made using an Ar flux of $20 \mathrm{sccm}$ and a power of $85 \mathrm{~W}$, providing a deposition rate of $0.2 \AA / \mathrm{s}$. To prevent post-oxidation, the resultant $\mathrm{Fe}_{0.2} \mathrm{Ni}_{0.8} / \mathrm{C}$ paper GDL was stored in a desiccator in vacuo.

The working electrode, for electrochemical water splitting, was obtained by gas transport phosphorization. Specifically, $0.3 \mathrm{~g}$ of the $\mathrm{P}$ red was loaded into an alumina combustion boat and placed at the beginning of the hot zone of a programmable tube furnace (Lenton), equipped with a quartz tube (inner $\varnothing=25 \mathrm{~mm}$ ), and the $\mathrm{Fe}_{0.2} \mathrm{Ni}_{0.8} / \mathrm{C}$ paper GDL specimen $(2.4 \mathrm{~cm} \times 10 \mathrm{~cm}$ ) was placed in the hot zone of the furnace next to the $\mathrm{P}$ red at a distance of $\approx 3 \mathrm{~cm}$. The phosphorization was conducted under continuous Ar gas flow of $100 \mathrm{~mL} / \mathrm{min}$. The system was heated to $500{ }^{\circ} \mathrm{C}$ at $20^{\circ} \mathrm{C} / \mathrm{min}$, held there for $1 \mathrm{~h}$, and cooled to $250{ }^{\circ} \mathrm{C}$ at $5{ }^{\circ} \mathrm{C} / \mathrm{min}$ and kept at this temperature for $12 \mathrm{~h}$. The as-synthesized electrode was stored under ambient conditions.

Electrocatalytic testing. All electrochemical measurements were carried out in a three-electrode set-up at room temperature under moderate Ar bubbling ( $\approx 1$ bubble/s) while stirring at $150 \mathrm{rpm}$ (IKA RCT basic). A Metrohm saturated calomel electrode (SCE) was used as the reference electrode. A graphite rod with length $=150 \mathrm{~mm}$ and $\varnothing=6 \mathrm{~mm}$ and a Pt wire with $\varnothing=0.25 \mathrm{~mm}$ were employed as counter electrodes for HER and OER, respectively. The as-synthesized Fe-Ni phosphide/C paper GDL was used as the 
working electrode. The acid and alkaline electrolytes for HER were $400 \mathrm{~mL}$ of degassed $0.5 \mathrm{M} \mathrm{H}_{2} \mathrm{SO}_{4}$ and $1 \mathrm{M} \mathrm{KOH}$, respectively, while all electrochemical OER measurements were conducted under alkaline conditions of degassed $1 \mathrm{M} \mathrm{KOH}(400 \mathrm{~mL})$.

The electrochemical data were collected using Metrohm Autolab PGSTAT302N potentiostats. Line scan voltammetry (LSV) was performed at a scan rate of $2 \mathrm{mV} / \mathrm{s}$ applying internal-resistance $(i R)$ compensation. All potentials are given with respect to reversible hydrogen electrode $\left(\mathrm{V}_{\mathrm{RHE}}\right)$ potential, which was determined for each reaction and electrolyte individually.

The electrode stability study was carried out by accelerated degradation testing (ADT) using cyclic voltammetry (CV) at a scan rate of $50 \mathrm{mV} / \mathrm{s}$ between the specified potentials for continuous 2000 cycles. The durability test was carried out by means of chronopotentiometry (CP) at the fixed current density of $20 \mathrm{~mA} / \mathrm{cm}^{2}$ while monitoring the variation of applied potential during $60 \mathrm{~h}$. Additional CP stability testing was conducted by changing stepwise the current density according to the following profile: $3 \mathrm{~h} @$ $5 \mathrm{~mA} / \mathrm{cm}^{2} \rightarrow 3 \mathrm{~h} @ 10 \mathrm{~mA} / \mathrm{cm}^{2} \rightarrow 3 \mathrm{~h} @ 15 \mathrm{~mA} / \mathrm{cm}^{2} \rightarrow 3 \mathrm{~h} @ 20 \mathrm{~mA} / \mathrm{cm}^{2}$.

Characterization. In the current study, the as-prepared electrode as well as the used electrodes after electrocatalyt-ic testing were characterized.

Powder X-ray diffraction (XRD) data were collected on a X'Pert PRO diffractometer (PANalytical) equipped with $\mathrm{Cu} \mathrm{K} \alpha$ radiation $(\lambda=1.541874 \AA$ ) and a PIXcel detector. Data were collected using BraggBrentano geometry in the $2 \theta 15-80^{\circ}$ range with a scan speed of $0.01 \%$. The XRD patterns were matched to International Centre for Diffrac-tion Data (ICDD) PDF-4 database using HighScore soft-ware package (PANalytical). For the unit cell parameter estimation, Ge (99.999\%) was used as an internal standard. The parameters were calculated from least-squares refinements using the WinCSD software package. 15

The morphology and the chemical composition of the samples was studied by scanning electron microscopy (SEM) using a Quanta 650 FEG ESEM microscope (FEI), fitted with an INCA Energy 350 system (Oxford Instruments) for energy-dispersive X-ray spectroscopy (EDX).

Raman spectroscopy measurements were carried out on an alpha300 R confocal Raman microscope (WITec) using a $532 \mathrm{~nm} \mathrm{Nd:YAG} \mathrm{laser} \mathrm{for} \mathrm{excitation.} \mathrm{The} \mathrm{laser} \mathrm{beam} \mathrm{with} \mathrm{P}=0.5 \mathrm{~mW}$ was focused on the electrode piece by a $\square 50$ lens (Zeiss); and the spectra were collected with 600 groove/mm grating using 25 acquisitions with a $2 \mathrm{~s}$ acquisi-tion time.

Computational Methodology. DFT calculations were performed using the Quantum Espresso simulation pack-age.16 Projector augmented wave (PAW) pseudopotentials were used with Perdew-Burke-Ernzerhof (PBEsol) ex-change correlation functionals. A k-mesh with $4 \square 4 \square 4$ points was used for structural relaxations. The unit cell dimensions were taken from the work of Donohue and coworkers, 17 and the positions were fully relaxed for all the compounds. From the relaxed structures, the density of states (DOS) was calculated in a k-mesh with 10x10x10 points. The projected DOS (PDOS) was averaged over the different atoms of the same type.

\section{RESULTS}

A simple and effective method provides $\mathrm{Fe} 0.2 \mathrm{Ni0} .8 \mathrm{P} 2 / \mathrm{C}$ paper GDL electrode. Thin carbon paper is a porous ma-terial composed of a dense array of randomly tangled carbon fibers, which provide an electrically conductive pathway for current collection in fuel cell technology.18 This type of GDL is designed to replace a woven thick carbon cloth GDL in applications, where thin GDL is a critical factor. Notably, commercially available carbon paper is not active in either cathodic HER or anodic OER half reactions of water electrolysis. At the same time, we hypothesized that carbon paper can be a good supporting material for the HER/OER catalysts, providing an excellent electronic connection between the catalyst and the electrode. To investigate the possibility of synthesizing an active electrode for electrochemical water splitting, we tested whether the emerging earth-abundant transition metal phosphide electrocatalyst could be anchored on the as-received carbon paper, without any pre-treatment of the GDL. For this purpose, we first deposited a 200-nm-thick layer of Permalloy on both sides of a carbon paper GDL by a robust sputtering method. A key criterion in selecting magnetic Permalloy was the fact that it consists of both $\mathrm{Fe}$ and $\mathrm{Ni}$, and the phosphide compounds of these TMs are active electrocatalysts in HER.19-20 The resultant $\mathrm{Fe} 0.2 \mathrm{Ni} 0.8 / \mathrm{C}$ paper GDL was further subjected to phosphorization via gas-transport reaction at $500{ }^{\circ} \mathrm{C} .13$

We first analyzed the phase composition of the electrode. According to XRD analysis, the as-synthesized electrode is a phase mixture of hexagonal graphitic supporting material and cubic P-rich negevite NiP2 phase with a pyrite-like structure (Figure 1a). X-ray diffraction shows no evidence of other phases. Hence, the reaction of Permalloy with phosphorous vapor led to the formation of single-phase iron-nickel diphosphide: $\mathrm{Fe} 0.2 \mathrm{Ni} 0.8+2 \mathrm{P}^{\uparrow}=>(\mathrm{Fe} 0.2 \mathrm{Ni} 0.8) \mathrm{P} 2$. Additionally, a lattice shift is observed as compared 
to pure NiP2, indicating that the substitution according to the formula Fe0.2Ni0.8P2 was successful. The refined cubic unit cell parameter for iron-nickel diphosphide, $a=5.445(2) \AA$, is slightly smaller than that of pure pyrite-like nickel diphosphide, $a=5.471 \AA$, indicating that Fe incorporation indeed occurs. ${ }^{17}$

We next examined the local structure of the as-prepared electrode by Raman spectroscopy (Figure 1b), and the results are in line with the XRD analysis. The spectrum of the as-received carbon paper GDL shows three prominent bands centered around 1350, 1589, and 2710 (not shown) $\mathrm{cm}^{-1}$, which are associated with the D, G, and 2D bands of graphite, respectively. The measurement presented in Figure $1 \mathrm{~b}$ further shows that two new Raman modes, at around 241 and $433 \mathrm{~cm}^{-1}$, are observed in the asprepared electrode. These bands represent $\mathrm{P}_{2}$ libration $\left(E_{\mathrm{g}}\right)$ and $\mathrm{P}-\mathrm{P}$ in-phase stretch $\left(A_{\mathrm{g}}\right)$ in a cubic $\mathrm{NiP}_{2}$ phase with a pyrite-like structure. ${ }^{21}$
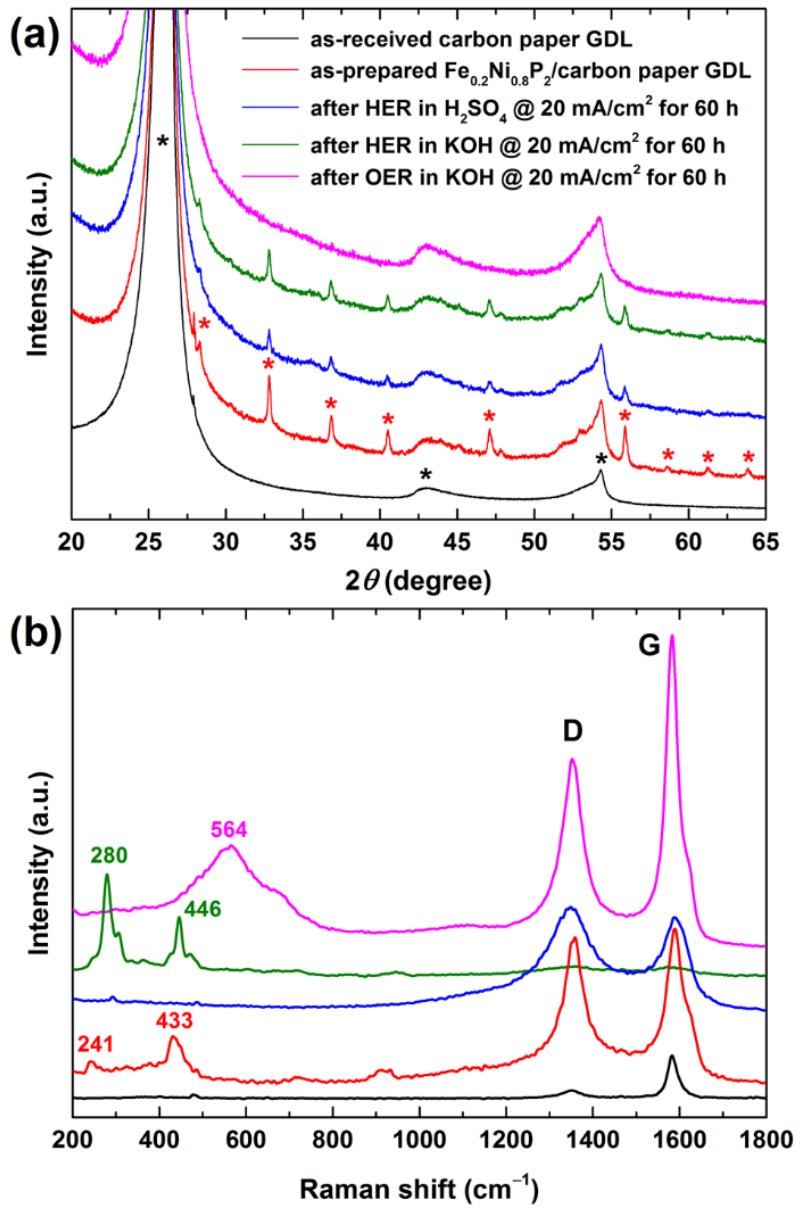

Figure 1. XRD patterns (a) and Raman spectra (b) of as-received carbon paper, as-prepared $\mathrm{Fe}_{0.2} \mathrm{Ni}_{0.8} \mathrm{P}_{2} / \mathrm{C}$ paper GDL electrode and the same electrode after HER and OER chronopotentiometric durability testing at $20 \mathrm{~mA} / \mathrm{cm}^{2}$ for $60 \mathrm{~h}$. Black and red stars in (a) correspond to the positions of the most intense Bragg reflections expected for graphitic carbon (ICDD no. 00-041-1487, hexagonal, $P 6_{3} / m m c$ ) and negevite $\mathrm{NiP}_{2}$ phase (ICDD no. 04-003-2351, cubic, $P a-3)$, respectively.

The catalyst is nanostructured and chemically uniform. We further analyzed the morphology and the chemical composition of the resultant electrode by means of SEM and EDX methods, respectively. The SEM image presented in Figure 2a shows the morphology of the $\mathrm{Fe}-\mathrm{Ni}$ diphosphide supported on carbon paper GDL, revealing homogeneous anchoring of the catalyst onto carbon fibers $(\varnothing=8-10 \mu \mathrm{m})$. $\mathrm{Fe}_{0.2} \mathrm{Ni}_{0.8} \mathrm{P}_{2}$ across the sample exhibits nanostructured appearance of non-uniform randomly orientated crystals with a closely associated microstructure (Figure $2 \mathrm{~b}$ ).

The particle size distribution was estimated to range from around 60 to $240 \mathrm{~nm}$; such a broad distribution is typical for gas-transport-reaction products. 
We next examined the chemical composition of the electrode surface using element-specific EDX mapping (Figure 2c). The respective EDX maps highlight the homogeneous distribution of Fe, $\mathrm{Ni}$, and $\mathrm{P}$ elements on the surface of carbon fibers, suggesting that the catalyst is a single-phase negevite, devoid of any secondary phases. EDX analysis also reveals that the $\mathrm{Fe} / \mathrm{Ni} / \mathrm{P}$ atomic ratio in the obtained electrode is 1:4.3:9.4, which agrees fairly well with the expected sample composition $\mathrm{Fe}_{0.2} \mathrm{Ni}_{0.8} \mathrm{P}_{2}$, corresponding to a $1: 4: 10$ ratio.

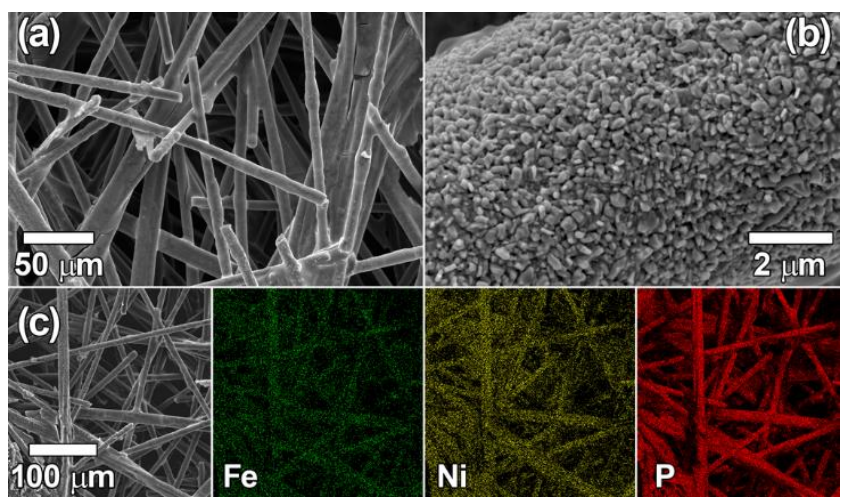

Figure 2. Low (a) and high (b) magnification SEM images, as well as EDX mapping for $\mathrm{Fe}_{0.2} \mathrm{Ni}_{0.8} \mathrm{P}_{2} / \mathrm{C}$ electrode (c).

$\mathrm{Fe}_{0.2} \mathrm{Ni}_{0.8} \mathrm{P}_{2}$ supported on carbon paper GDL is an active catalyst for both HER/OER. Our nanostructured phase-pure $\mathrm{Fe}_{0.2} \mathrm{Ni}_{0.8} \mathrm{P}_{2}$, uniformly deposited over carbon paper GDL, was further evaluated in the cathodic and anodic half-reaction of electrochemical water splitting at room temperature. The mass density of the catalytically relevant $\mathrm{Fe}_{0.2} \mathrm{Ni}_{0.8} \mathrm{P}_{2}$ phase was gravimetrically estimated to be 1.07 $\mathrm{mg} / \mathrm{cm}^{2}$ using a Cubis MCM36 balance (Sartorius). The results of the electrocatalytic experiments are summarized in Table 1 and Figure 3.

Table 1. Electrocatalytic performance of the electrode.

\begin{tabular}{|l|c|c|c|}
\hline Reaction & $\begin{array}{c}\text { HER in } \\
0.5 \mathrm{M} \mathrm{H}_{2} \mathrm{SO}_{4}\end{array}$ & $\begin{array}{c}\text { HER in } \\
1 \mathrm{M} \mathrm{KOH}\end{array}$ & $\begin{array}{c}\text { OER in } \\
1 \mathrm{M} \mathrm{KOH}\end{array}$ \\
\hline$\eta_{\text {onset }}$ onset potential for driving $1 \mathrm{~mA} / \mathrm{cm}^{2}(\mathrm{~V})$ & 0.117 & 0.175 & 1.092 \\
\hline $\begin{array}{l}\eta_{10}, \text { current densities } \\
\text { of } 10 \mathrm{~mA} / \mathrm{cm}^{2}(\mathrm{~V})\end{array}$ & 0.171 & 0.250 & 1.371 \\
\hline $\begin{array}{l}\eta_{20}, \text { current densities } \\
\text { of } 20 \mathrm{~mA} / \mathrm{cm}^{2}(\mathrm{~V})\end{array}$ & 0.190 & 0.275 & 1.402 \\
\hline $\begin{array}{l}j_{0}, \text { exchange current } \\
\text { density }\left(\mathrm{mA} / \mathrm{cm}^{2}\right)\end{array}$ & $6.841^{-3}$ & $3.1610^{-3}$ & $2.8810^{-4}$ \\
\hline Tafel slope $(\mathrm{mV} / \mathrm{dec})$ & 55.3 & 72.2 & 49.3 \\
\hline
\end{tabular}

We first tested whether the as-prepared electrode is active in HER conducted in acidic, $2 \mathrm{H}^{+}+2 e^{-} \Rightarrow \mathrm{H}_{2} \uparrow$, and alkaline, $2 \mathrm{H}_{2} \mathrm{O}+2 e^{-} \Rightarrow \mathrm{H}_{2} \uparrow+2 \mathrm{OH}^{-}$, electrolytes, which were $0.5 \mathrm{M}$ solution of sulfuric acid and $1.0 \mathrm{M}$ solution of potassium hydroxide, respectively. We found that $\mathrm{Fe}_{0.2} \mathrm{Ni}_{0.8} \mathrm{P}_{2} / \mathrm{C}$ paper GDL electrode exhibits strong catalytic currents on cathodic polarization in both type of electrolytes. In terms of HER overpotentials, the activity of the catalyst in acidic conditions is approximately $50 \%$ higher than in alkaline medium, while showing approximately twice the exchange current density (Table 1). Notably, at high overpotentials, $>200 \mathrm{mV}$, the catalytic activity in alkaline medium becomes slightly higher than in acidic medium. More importantly, the electrode is eventually able to drive cathodic currents higher than $55 \mathrm{~mA} / \mathrm{cm}^{2}$ in both types of electrolytes, while having only $\approx 1.1 \mathrm{mg} / \mathrm{cm}^{2}$ mass loading of electrocatalytic phase (Figure 3a). Tafel slopes of about 55 and $72 \mathrm{mV} /$ dec were estimated in $\mathrm{H}_{2} \mathrm{SO}_{4}$ and $\mathrm{KOH}$ 
electrolytes, respectively, pointing towards Volmer-Heyrovsky mechanistic scenario during the HER processes. ${ }^{22}$

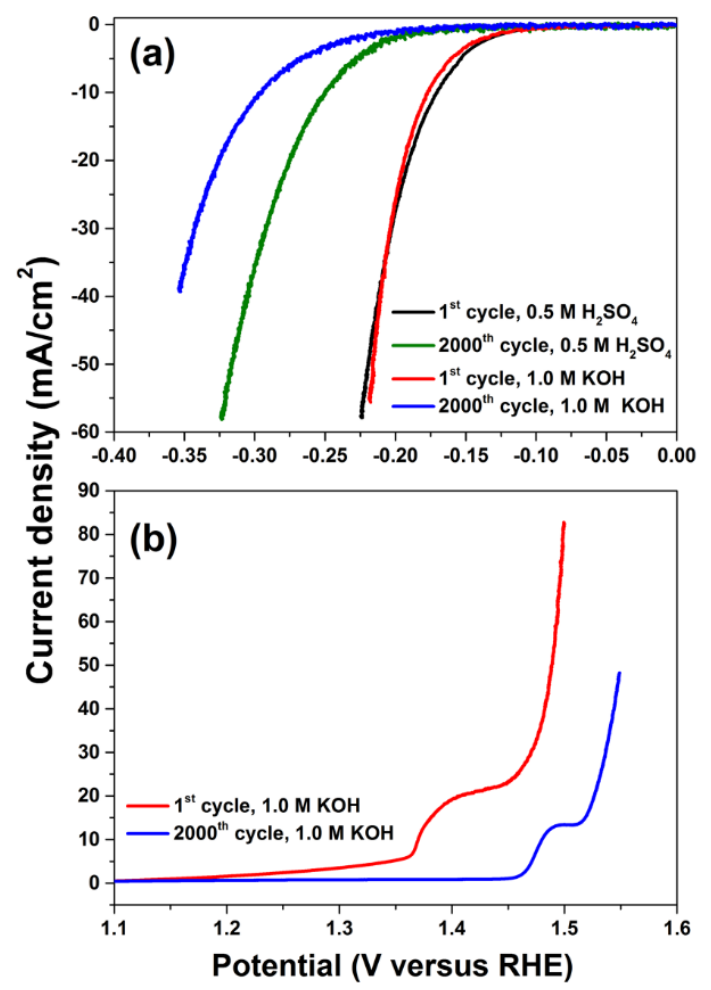

Figure 3. HER cathodic (a) and OER anodic (b) polarization curves before and after accelerated degradation testing (ADT) for 2000 consecutive cycles for the as-prepared electrode. ADT was carried out by sweeping the potential at a rate of $50 \mathrm{mV} / \mathrm{s}$ in a range of $-400-60,-400-260$, and $400-1600 \mathrm{mV}_{\mathrm{RHE}}$ for HER in $0.5 \mathrm{M} \mathrm{H}_{2} \mathrm{SO}_{4}$ and $1.0 \mathrm{M} \mathrm{KOH}$ and OER in $1.0 \mathrm{M} \mathrm{KOH}$, respectively. All polarization curves are $i R$-compensated.

These results suggested that $\mathrm{Fe}_{0.2} \mathrm{Ni}_{0.8} \mathrm{P}_{2}$ is an active Pt-free HER catalyst in acid and alkaline electrolytes. Moreover, it has also been reported that earth-abundant mixed $\mathrm{Ni}-\mathrm{Fe}$ compounds are promising OER catalysts. ${ }^{23}$ Therefore, we further investigated the electrocatalytic activity of the as-prepared electrode in OER using $1.0 \mathrm{M} \mathrm{KOH}$ as electrolyte. The electrode demonstrates noticeable oxidation current density starting from an overpotential of approximately $1.2 \mathrm{~V}_{\mathrm{RHE}}$ with a shoulder peak at $\approx 1.37 \mathrm{~V}_{\mathrm{RHE}}$ (Figure 3b), which is attributed to $\mathrm{Ni}^{2+} / \mathrm{Ni}^{3+}$ redox transformation. ${ }^{24}$ Beyond this overpotential, the oxidation current rose sharply as a result of four electron evolution of $\mathrm{O}_{2}$ in alkaline medium, $4 \mathrm{OH}^{-} \Rightarrow \mathrm{O}_{2} \uparrow+2 \mathrm{H}_{2} \mathrm{O}+4 e^{-}$, as visualized by oxygen bubbles forming on the electrode surface. The overall current density of about $83 \mathrm{~mA} / \mathrm{cm}^{2}$ at 1.5 $\mathrm{V}_{\mathrm{RHE}}$ was reached for the electrode, and the Tafel slope was estimated to be around 49 $\mathrm{mV} /$ dec. Thus, our electrocatalytic testing shows that the $\mathrm{Fe}_{0.2} \mathrm{Ni}_{0.8} \mathrm{P}_{2}$ phase is a highperforming electrocatalyst for OER. This result is not surprising, because the other two nickel phosphide phases, namely $\mathrm{Ni}_{2} \mathrm{P}$ and $\mathrm{Ni}_{4} \mathrm{P}_{5}$, were recently reported to be active towards OER. ${ }^{25-26}$

Electrode shows instability during ADT but good stability during CP testing. One important question arising from the high electrocatalytic activity of $\mathrm{Fe}_{0.2} \mathrm{Ni}_{0.8} \mathrm{P}_{2} / \mathrm{C}$ paper GDL is whether this electrode is 
stable and durable during water splitting, because both OER and HER processes are conducted under harsh chemical conditions while applying an electrical potential. Therefore, we characterized the stability of the as-prepared electrode by means accelerated degradation. The results of the ADT experiments presented in Figure 3 show that the repeated cycling of $\mathrm{Fe}_{0.2} \mathrm{Ni}_{0.8} \mathrm{P}_{2} / \mathrm{C}$ paper GDL electrode for 2000 consecutive cycles in HER and OER leads to significant cathodic and anodic shifts, respectively, of the linear onset potential sweeps, as compared to the first cycles. Hence, the data indicates that the electrode is unstable for HER/OER during ADT.

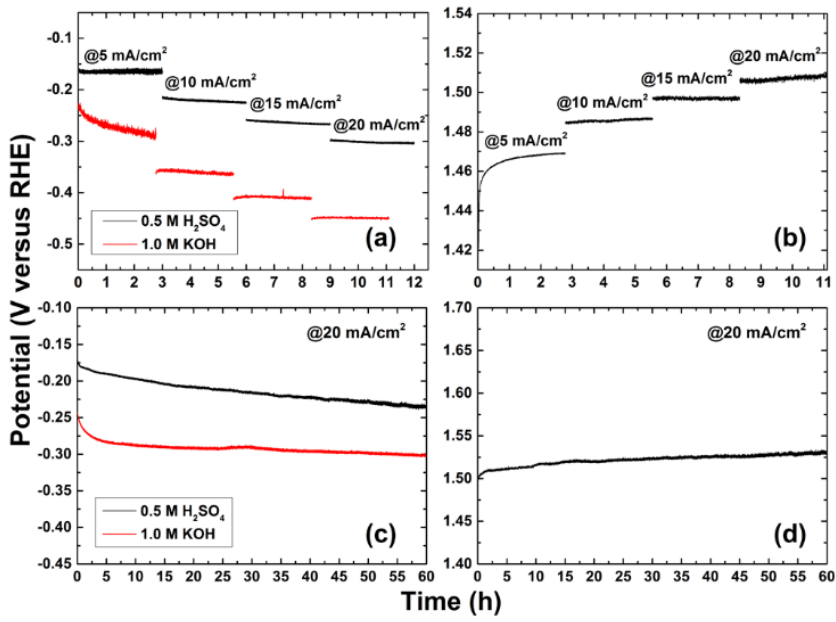

Figure 4. Stepwise $(a, b)$ and continuous $(c, d)$ chronopotentiometric profiles of the synthesized electrode as a test for its durability in HER (a, c) and OER (b, d).

We then wondered whether the electrode can generate stable currents during HER and OER. To answer this question, we subjected the electrode to stepwise and continuous durability testing via chronopotentiometry (Figure 4). In all cases, the applied overpotentials were found to increase initially, and stabilize thereafter showing only a slight increase over time. These results reveal that, after the initial stage of the testing, the electrode exhibits a reasonably good long-term stability towards HER and OER. Importantly, the electrode is able to generate stable anodic and cathodic currents for more than two days during CP testing.

During HER, $\mathrm{Fe}_{0.2} \mathrm{Ni}_{0.8} \mathrm{P}_{2}$ partially dissolves and exhibits coke deposition. To relate the observed stability and durability data to the possible structural, microstructural, and compositional changes of the electrode, we next examined the samples after durability testing for $60 \mathrm{~h}$ by XRD, Raman spectroscopy, SEM and EDX.

Structural characterization of the electrodes used in HER (Figure 1a) reveals that the $\mathrm{Fe}_{0.2} \mathrm{Ni}_{0.8} \mathrm{P}_{2}$ preserved its bulk structure. The diphosphide lattice parameters were calculated to be $a=5.438(4) \AA$ and $a=5.450(1) \AA$ after acid and alkaline HER, respectively, and the obtained parameters differ not more than $3 \sigma$ compared with as-prepared $\mathrm{Fe}_{0.2} \mathrm{Ni}_{0.8} \mathrm{P}_{2}(a=5.445(2) \AA)$. The EDX analyses show that the electrodes are enriched in $\mathrm{P}$ in comparison to their initial compositions, exhibiting the $\mathrm{Fe} / \mathrm{Ni} / \mathrm{P}$ atomic ratios of 1:4.4:12.1 and 1:5.3:10.9 after HER in acid and alkaline electrolytes, respectively. Fe/Ni ratio is maintained under acidic conditions but a leaching of $\mathrm{Fe}$ is observed for basic conditions. EDX results indicate corrosion of the metal diphosphide phase through partial dissolution during HER. 


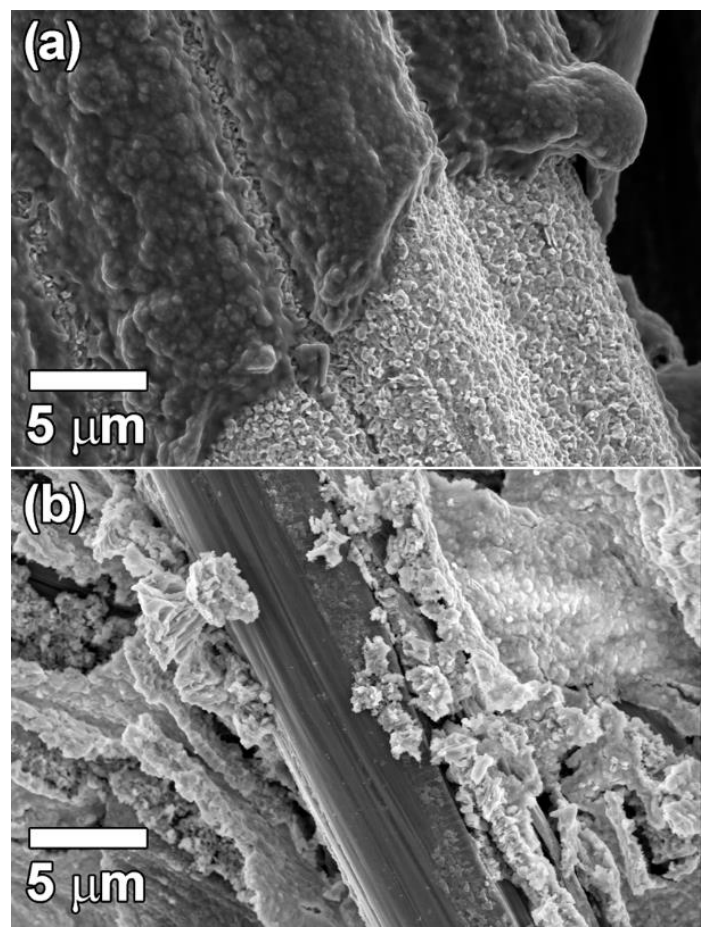

Figure 5. SEM images of electrodes after durability testing at $20 \mathrm{~mA} / \mathrm{cm}^{2}$ for $60 \mathrm{~h}$ in acidic HER (a) and OER (b).

Our further analysis of the Raman spectra of the electrodes used in HER (Figure 1b) shows the loss of distinct modes at 241 and $433 \mathrm{~cm}^{-1}$ of the $\mathrm{Ni}_{2} \mathrm{P}$ structure, and the appearance of the new peaks/modes at around 280 and $446 \mathrm{~cm}^{-1}$ for the electrode used in alkaline HER. These bands seem to stem from nickel hydroxide, which is characterized by the presence of two modes at 318 and $449 \mathrm{~cm}^{-1}{ }^{27}$ The observed downshift of the modes is most likely a result of $\mathrm{Ni}$ substitution by Fe. Besides these new peaks, significant sign of coke deposition in the form of the oxidized carbon was observed in the Raman spectrum of the electrode used in acid HER. This is reflected by the presence of two very broad characteristic modes in the $1300-1700 \mathrm{~cm}^{-1}$ range. We further confirm coke deposition by SEM-EDX analysis of the electrode, which has a dark amorphous-like appearance on the surface of the fibers (Figure 5a). Thus, these data suggest that the surface of the HER electrodes in acid electrolyte undergoes poisoning by carbon coke, which originates either from the graphite counter electrode or from the carbon paper support.

During OER, $\mathrm{Fe}_{0.2} \mathrm{Ni}_{0.8} \mathrm{P}_{2}$ undergoes complete chemical transformation into poorly crystalline hydroxide. We next studied the effect of the OER process on the $\mathrm{Fe}_{0.2} \mathrm{Ni}_{0.8} \mathrm{P}_{2} / \mathrm{C}$ paper GDL electrode. For this, we analyzed the resultant electrode after OER durability testing at $20 \mathrm{~mA} / \mathrm{cm}^{2}$ for $60 \mathrm{~h}$. As shown in Figure 1, the electrode undergoes severe modifications during OER, since no signature of $\mathrm{Fe}_{0.2} \mathrm{Ni}_{0.8} \mathrm{P}_{2}$ was found by XRD or Raman spectroscopy. Moreover, the Raman spectrum of the used electrode shows a broad band centered around $560 \mathrm{~cm}^{-1}$, which is associated with defective/disordered Fe-containing $\mathrm{Ni}(\mathrm{OH})_{2} \cdot{ }^{24,} 28$ Interestingly, SEM-EDX reveals two distinct appearances in the sample: uncoated carbon fibers of raw carbon paper as well as flat structures lacking particulate structure regions or crystal faceting at the surface (Figure 5b). EDX shows that the latter structures do not have any signature of phosphorous element but of oxygen instead, and exhibit a Fe/Ni atomic ratio of 1:4.9. In light of this microscopy data coupled with the results of XRD and Raman spectroscopy, the flat aggregates with a lack of particulate structure can be classified as poorly crystalline iron-containing nickel hydroxide. This seems to suggest that the $\mathrm{Fe}_{0.2} \mathrm{Ni}_{0.8} \mathrm{P}_{2}$ phase is not stable under OER conditions and undergo complete chemical transformation into amorphous-like hydroxide, which further catalyzes OER.

\section{DISCUSSION}

High electrocatalytic activity correlates with electronic structure of mixed iron-nickel diphosphide. We developed a robust method to produce mixed Fe-Ni diphosphide electrocatalyst supported on as- 
received carbon paper GDL, allowing production of nanostructured single-phase material. $\mathrm{Fe}_{0.2} \mathrm{Ni}_{0.8} \mathrm{P}_{2}$ with pyrite-type structure generated using Permalloy as the precursor. Notably, nickel diphosphide $\mathrm{NiP}_{2}$ forms cubic $\mathrm{Pa}-3$ pyrite-type structure only under high pressure of $1.5-6.5 \mathrm{GPa}^{17}$ Under ambient pressure syntheses, another monoclinic $C 2 / c$ modification with drastically different structural motif where all $\mathrm{P}$ atoms are connected in one-dimensional chains is usually obtained. ${ }^{29-30}$ This interesting finding suggests that, in the current study, the high-pressure modification of nickel diphosphide was stabilized by $\mathrm{Fe}$ doping. More importantly, we further found that iron enters the cubic crystal structure of negevite $\mathrm{NiP}_{2}$ and induces a high activity towards HER/OER, suggesting a positive role of iron in the reactions.

One possible mechanism of high electrocatalytic activity is that iron modifies the electronic structure of $\mathrm{NiP}_{2}$, resulting in its high activity. To support this suggestion, we applied first-principles DFT calculations to compare the electronic structure of pure and iron-substituted $\mathrm{FeNi}_{3} \mathrm{P}_{8}$ analog with cubic pyrite-like structure (Figures 6a and $6 \mathrm{~b}$ ). Favorably for electrocatalysis, both prototypes were calculated to be metallic in nature (Figures $6 \mathrm{c}$ and $6 \mathrm{~d}$ ), assuring good electronic conductivity of the electrode. More interestingly, we found that their bulk electronic structures are quite different. In particular, the $\mathrm{Fe} 3 d$ orbitals are significantly shifted towards higher energy, resulting in the increase of the overall DOS at the Fermi level for the $\mathrm{FeNi}_{3} \mathrm{P}_{8}$ prototype (Figure $6 \mathrm{~h} c f .6 \mathrm{~g}$ ).

Unstable at ambient pressure, cubic pyrite-structure of $\mathrm{NiP}_{2}$ has only few bands that cross the Fermi level at $\Gamma$ point (Figures $6 \mathrm{c}$ and $6 \mathrm{e}$ ). Doping this structure with Fe greatly increases the metallic character of the structure, since several bands cross the Fermi level along every direction of the Brillouin zone (Figures 6d and 6f). In addition to appearance of $\mathrm{Fe} 3 d$ states at the Fermi level, the Ni3d states in $\mathrm{FeNi}_{3} \mathrm{P}_{8}$ are broadened in comparison with the Ni3d states of pure $\mathrm{NiP}_{2}$ (Figures $6 \mathrm{e} c f$. $6 \mathrm{~h}$ ). Previously, we have shown that the development of a broad band structure of other nickel phosphide, namely $\mathrm{Ni}_{2} \mathrm{P}$, with $\mathrm{Al}$ doping resulted in enhanced electrocatalytic activity as compared to pure $\mathrm{Ni}_{2} \mathrm{P} .{ }^{12}$ Most likely, here we have a similar situation, when the performance of $\mathrm{NiP}_{2}$ towards HER/OER is enhanced by $\mathrm{Fe}$ incorporation as a result of lowering activation energy of hydrogen or oxygen adsorption on the catalyst surface. This is due to the development of a broad overall band structure extending over the Fermi level. ${ }^{31-32}$ Another potential mechanism is that a significant restructuring of the surface may occur under highly acidic or alkaline conditions while applying the electrical potential, resulting in synergetic $\mathrm{Fe} / \mathrm{Ni}$ active sites ${ }^{33-34}$ In situ studies of the catalyst surface are necessary to clarify this issue. 
(a)

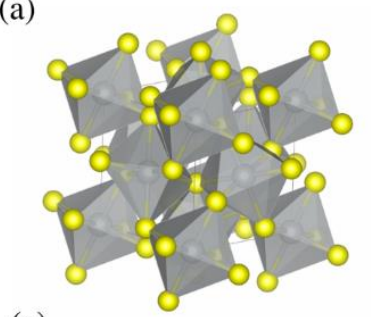

(c)

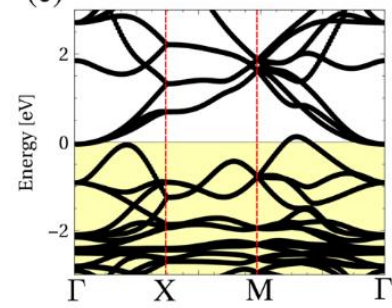

(e)
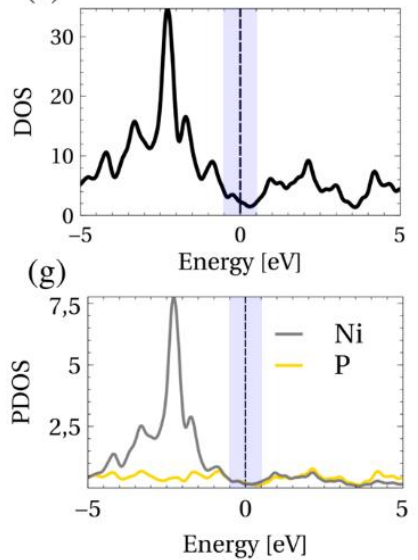

(b)

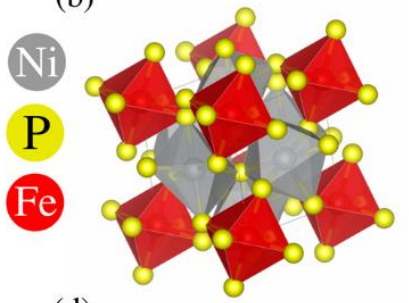

(d)

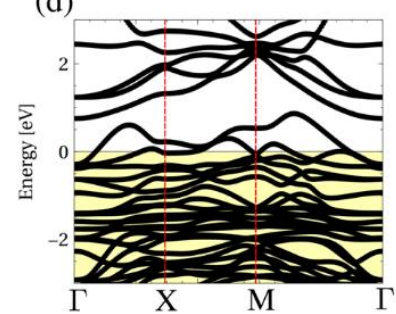

(f)
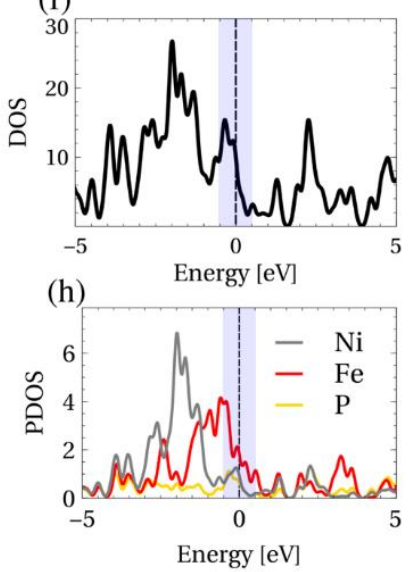

Figure 6. Crystal structure (a, b), band structure (c, d), DOS (e, f) and PDOS (g, h) for pure $\mathrm{NiP}_{2}(\mathrm{a}, \mathrm{c}, \mathrm{e}, \mathrm{g})$ and its relaxed $\mathrm{Fe}$-substituted $\mathrm{FeNi}_{3} \mathrm{P}_{8}$ analog $(\mathrm{b}, \mathrm{d}, \mathrm{f}, \mathrm{h})$. The Fermi level is indicated with a dashed line.

Mechanisms of the electrode degradation during HER/OER. Discovery of high electrocatalytic activity of the $\mathrm{Fe}, \mathrm{Co}, \mathrm{Ni}, \mathrm{Cu}, \mathrm{Mo}$, and $\mathrm{W}$ TM phosphides has placed this class of compounds as one of the most promising earth-abundant candidates to replace PGM-based electrocatalysts in water electrolysis to generate hydrogen. Accordingly, during the last few years, great progress has been made in the synthesis, nanostructuring, testing and understanding of the phosphide electrocatalysts. ${ }^{11,19-20}$ Besides this great progress, the stability and durability of the phosphides under water electrolysis conditions remain to be strongly improved. Therefore, we studied the chemistry of our electrode $\mathrm{Fe}_{0.2} \mathrm{Ni}_{0.8} \mathrm{P}_{2} / \mathrm{C}$ paper GDL degradation under harsh acidic and alkaline conditions of HER/OER.

In general, nickel phosphides are quite stable in either acid or basic conditions. In reaction of phosphide with acid in non-oxidizing environment phosphine should form: $\mathrm{NiP}_{2}+6 \mathrm{H}^{+} \Rightarrow \mathrm{Ni}^{2+}+2 \mathrm{PH}_{3} \uparrow$. Typically, the evolved phosphine $\mathrm{PH}_{3}$ moves to the air-liquid interface, where it ignites upon the reaction with oxygen from air. Given that we did not observe any signature of this reaction during our HER measurements, we can safely omit such a degradation mechanism. At the same time, our analyses of the electrodes after HER suggest a partial dissolution of the $\mathrm{Fe}_{0.2} \mathrm{Ni}_{0.8} \mathrm{P}_{2}$ phase with the signature of the sulfate and phosphate anions at the surface. This could suggest the following dissolution reactions $\mathrm{MP}_{2}+\mathrm{H}_{2} \mathrm{SO}_{4}$ $+2 \mathrm{H}_{2} \mathrm{O}+3 \mathrm{O}_{2} \Rightarrow \mathrm{MSO}_{4}+2 \mathrm{H}_{3} \mathrm{PO}_{4}$ and $\mathrm{MP}_{2}+6 \mathrm{KOH}+3 \mathrm{O}_{2} \Rightarrow \mathrm{M}(\mathrm{OH})_{2}+2 \mathrm{~K}_{3} \mathrm{PO}_{4}+2 \mathrm{H}_{2} \mathrm{O}$ in acid and alkaline electrolytes, respectively. Therein, the most likely source of oxygen is the OER taking place at the graphite counter electrode. Our data also showed that the electrode displays fast corrosion under ADT, while in the case of the long-term durability testing the electrode demonstrates only moderate corrosion (Figures $3 \mathrm{a} c f .4 \mathrm{a}$ and $4 \mathrm{c}$ ). This is probably due to the accelerated degradation through fast oxidation of $\mathrm{Fe}_{0.2} \mathrm{Ni}_{0.8} \mathrm{P}_{2}$ under positive sweeping potentials of the ADT measurement. This also suggests that the observed higher degree of electrode degradation during ADT in alkaline electrolyte (Figure $3 \mathrm{a}$ ) is a result of applying higher positive upper potential during ADT in $\mathrm{KOH}$ (260 vs $60 \mathrm{mV}_{\mathrm{RHE}}$ ). 
Notably, there is the possibility that coke deposition could play a role in the loss of electrocatalytic activity during HER. To corroborate this, we washed out the coke from the tested electrode using acetone, which was confirmed by SEM, and then tested the electrode again in HER. We found that the electrode activity was not recovered after coke removal, suggesting a minimal impact of the coke deposition on the electrode stability.

Thus, the deactivation of $\mathrm{Fe}_{0.2} \mathrm{Ni}_{0.8} \mathrm{P}_{2} / \mathrm{C}$ paper GDL electrode during HER in both type of electrolytes seems not be due to the peeling off the electrocatalyst from carbon fibers or its poisoning by carbon coke, but rather a simple corrosion of $\mathrm{Fe}_{0.2} \mathrm{Ni}_{0.8} \mathrm{P}_{2}$ phase, which occurs via continuous oxidative dissolution according to the aforementioned reactions under applied positive potential.

In sharp contrast to HER, our characterization of the electrode used in OER shows that $\mathrm{Fe}_{0.2} \mathrm{Ni}_{0.8} \mathrm{P}_{2}$ rapidly undergoes complete chemical transformation. The most prominent end product of this transformation is amorphous Fe-containing nickel(II) hydroxide, which may form by the reaction $\mathrm{MP}_{2}+$ $6 \mathrm{KOH}+3 \mathrm{O}_{2} \Rightarrow \mathrm{M}(\mathrm{OH})_{2}+2 \mathrm{~K}_{3} \mathrm{PO}_{4}+2 \mathrm{H}_{2} \mathrm{O}$. This amorphous mixed hydroxide can further catalyse OER and remain active and stable for at least $60 \mathrm{~h}$, which is in good agreement with the reported literature data. ${ }^{6,15-16,35-36}$

To conclude, the chemical composition of the metal phosphide phase and the corresponding additional valence band states could be optimized to achieve better stability of the electrocatalyst. Although the current research does not provide the exact mode of action during the degradation of the $\mathrm{Fe}_{0.2} \mathrm{Ni}_{0.8} \mathrm{P}_{2} / \mathrm{C}$ paper GDL directly under the reaction conditions, here we describe the first step toward understanding of the diphosphide phase corrosion during HER/OER. Importantly, this will allow for in situ high pressure $\mathrm{X}$-ray photoelectron spectroscopy studies that would piece together the chemical composition and stability of TM phosphide surface species, as well as their activity. This is the subject of our current efforts.

\section{AUTHOR INFORMATION}

\section{Corresponding Author}

*E-mail: yury.kolenko@inl.int.

Notes

The authors declare no competing financial interest.

\section{ACKNOWLEDGMENTS}

We thank all members of the Nanomaterials Synthesis Unit at the INL for their fruitful scientific and technical input, as well as Dr. X. Wang for his help with the electrocatalytic data analysis. This investigation has benefited from the financial support provided by the European Union Horizon 2020 NMP programme through the CritCat project under grant agreement no. 686053, as well as ERDF funds through the Portuguese Operational Programme for Competitiveness and Internationalization (COMPETE 2020), and National Funds through the Portuguese Foundation for Science and Technology (FCT), under the PrintPV project PTDC/CTM-ENE/5387/2014 (grant agreement no. 016663). J.D.C. thanks the FCT $\mathrm{PhD}$ grant SFRH/BD/79393/2011, while J.L.L. thanks Marie-Curie-ITN607904-SPINOGRAPH project for the $\mathrm{PhD}$ grant.

\section{REFERENCES}

1. $\quad$ Turner, J. A., A Realizable Renewable Energy Future. Science 1999, 285, 687-689.

2. Rostrup-Nielsen, J. R., Steam Reforming. In Handbook of Heterogeneous Catalysis, Wiley-VCH Verlag GmbH \& Co. KGaA: 2008; pp 2882-2905.

3. Trasatti, S., Water Electrolysis: Who First? J. Electroanal. Chem. 1999, 476, 90-91.

4. Krischer, K.; Savinova, E. R., Fundamentals of Electrocatalysis. In Handbook of Heterogeneous Catalysis, Wiley-VCH Verlag GmbH \& Co. KGaA: 2008; pp 1873-1905.

5. Vesborg, P. C. K.; Seger, B.; Chorkendorff, I., Recent Development in Hydrogen Evolution Reaction Catalysts and Their Practical Implementation. J. Phys. Chem. Lett. 2015, 6, 951-957.

6. Lee, Y.; Suntivich, J.; May, K. J.; Perry, E. E.; Shao-Horn, Y., Synthesis and Activities of Rutile $\mathrm{IrO}_{2}$ and $\mathrm{RuO}_{2}$ Nanoparticles for Oxygen Evolution in Acid and Alkaline Solutions. J. Phys. Chem. Lett. 2012, 3, 399-404.

7. Carmo, M.; Fritz, D. L.; Merge, J.; Stolten, D., A Comprehensive Review on Pem Water Electrolysis. Int. J. Hydrogen Energy 2013, 38, 4901-4934. 
8. Zou, X. X.; Zhang, Y., Noble Metal-Free Hydrogen Evolution Catalysts for Water Splitting. Chem. Soc. Rev. 2015, 44, 5148-5180.

9. Faber, M. S.; Jin, S., Earth-Abundant Inorganic Electrocatalysts and Their Nanostructures for Energy Conversion Applications. Energy Environ. Sci. 2014, 7, 3519-3542.

10. Chen, D. J.; Chen, C.; Baiyee, Z. M.; Shao, Z. P.; Ciucci, F., Nonstoichiometric Oxides as LowCost and Highly-Efficient Oxygen Reduction/Evolution Catalysts for Low-Temperature Electrochemical Devices. Chem. Rev. 2015, 115, 9869-9921.

11. Abbas, M. A.; Bang, J. H., Rising Again: Opportunities and Challenges for Platinum-Free Electrocatalysts. Chem. Mater. 2015, 27, 7218-7235.

12. Lado, J. L.; Wang, X. G.; Paz, E.; Carbo-Argibay, E.; Guldris, N.; Rodriguez-Abreu, C.; Liu, L. F.; Kovnir, K.; Kolen'ko, Y. V., Design and Synthesis of Highly Active Al-Ni-P Foam Electrode for Hydrogen Evolution Reaction. ACS Catal. 2015, 5, 6503-6508.

13. Wang, X.; Kolen'ko, Y. V.; Bao, X.-Q.; Kovnir, K.; Liu, L., One-Step Synthesis of SelfSupported Nickel Phosphide Nanosheet Array Cathodes for Efficient Electrocatalytic Hydrogen Generation. Angew. Chem. Int. Ed. 2015, 127, 8306-8310.

14. Wang, X. G.; Kolen'ko, Y. V.; Liu, L. F., Direct Solvothermal Phosphorization of Nickel Foam to Fabricate Integrated $\mathrm{Ni}_{2} \mathrm{P}-\mathrm{Nanorods} / \mathrm{Ni}$ Electrodes for Efficient Electrocatalytic Hydrogen Evolution. Chem. Commun. 2015, 51, 6738-6741.

15. Akselrud, L. G.; Zavalii, P. Y.; Grin, Y. N.; Pecharsky, V. K.; Baumgartner, B.; Wolfel, E., Use of the CSD Program Package for Structure Determination from Powder Data. Mater. Sci. Forum 1993, 133$136,335-340$.

16. Giannozzi, P., et al., Quantum Espresso: A Modular and Open-Source Software Project for Quantum Simulations of Materials. J. Phys. Condens. Matter 2009, 21.

17. Donohue, P. C.; Bither, T. A.; Young, H. S., High-Pressure Synthesis of Pyrite-Type Nickel Diphosphide and Nickel Diarsenide. Inorg. Chem. 1968, 7, 998-1001.

18. Barbir, F., Pem Fuel Cells : Theory and Practice, 2nd ed.; Elsevier/Academic Press: Amsterdam ; Boston, 2013, p 518.

19. Xiao, P.; Chen, W.; Wang, X., A Review of Phosphide-Based Materials for Electrocatalytic Hydrogen Evolution. Adv. Energy Mater. 2015, 5, 1500985.

20. Shi, Y. M.; Zhang, B., Recent Advances in Transition Metal Phosphide Nanomaterials: Synthesis and Applications in Hydrogen Evolution Reaction. Chem. Soc. Rev. 2016, 45, 1529-1541.

21. Zhuo, J. Q.; Caban-Acevedo, M.; Liang, H. F.; Samad, L.; Ding, Q.; Fu, Y. P.; Li, M. X.; Jin, S., High-Performance Electrocatalysis for Hydrogen Evolution Reaction Using Se-Doped Pyrite-Phase Nickel Diphosphide Nanostructures. ACS Catal. 2015, 5, 6355-6361.

22. Li, Y. G.; Wang, H. L.; Xie, L. M.; Liang, Y. Y.; Hong, G. S.; Dai, H. J., MoS 2 Nanoparticles Grown on Graphene: An Advanced Catalyst for the Hydrogen Evolution Reaction. J. Am. Chem. Soc. 2011, 133, 7296-7299.

23. Smith, R. D. L.; Prevot, M. S.; Fagan, R. D.; Zhang, Z. P.; Sedach, P. A.; Siu, M. K. J.; Trudel, S.; Berlinguette, C. P., Photochemical Route for Accessing Amorphous Metal Oxide Materials for Water Oxidation Catalysis. Science 2013, 340, 60-63.

24. Louie, M. W.; Bell, A. T., An Investigation of Thin-Film Ni-Fe Oxide Catalysts for the Electrochemical Evolution of Oxygen. J. Am. Chem. Soc. 2013, 135, 12329-12337.

25. Ledendecker, M.; Calderon, S. K.; Papp, C.; Steinruck, H. P.; Antonietti, M.; Shalom, M., The Synthesis of Nanostructured $\mathrm{Ni}_{5} \mathrm{P}_{4}$ Films and Their Use as a Non-Noble Bifunctional Electrocatalyst for Full Water Splitting. Angew. Chem. Int. Ed. 2015, 54, 12361-12365.

26. Stern, L. A.; Feng, L. G.; Song, F.; Hu, X. L., Ni $\mathrm{N}_{2} \mathrm{P}$ as a Janus Catalyst for Water Splitting: The Oxygen Evolution Activity of $\mathrm{Ni}_{2} \mathrm{P}$ Nanoparticles. Energy Environ. Sci. 2015, 8, 2347-2351.

27. Hall, D. S.; Lockwood, D. J.; Bock, C.; MacDougall, B. R., Nickel Hydroxides and Related Materials: A Review of Their Structures, Synthesis and Properties. Proc. R. Soc. A 2015, 471, 20140792.

28. Johnston, C.; Graves, P. R., In Situ Raman Spectroscopy Study of the Nickel Oxyhydroxide Electrode (NOE) System. Appl. Spectrosc. 1990, 44, 105-115.

29. Larsson, E., An X-Ray Investigation of the Ni-P System and the Crystal Structures of NiP and $\mathrm{NiP}_{2}$. Arkiv foer Kemi 1965, 23, 335-365.

30. Odile, J. P.; Soled, S.; Castro, C. A.; Wold, A., Crystal Growth and Characterization of the Transition-Metal Phosphides Copper Diphosphide, Nickel Diphosphide, and Rhodium Triphosphide. Inorg. Chem. 1978, 17, 283-286.

31. Kibsgaard, J.; Tsai, C.; Chan, K.; Benck, J. D.; Norskov, J. K.; Abild-Pedersen, F.; Jaramillo, T. F., Designing an Improved Transition Metal Phosphide Catalyst for Hydrogen Evolution Using Experimental and Theoretical Trends. Energy Environ. Sci. 2015, 8, 3022-3029. 
32. Moon, J.-S.; Jang, J.-H.; Kim, E.-G.; Chung, Y.-H.; Yoo, S. J.; Lee, Y.-K., The Nature of Active Sites of $\mathrm{Ni}_{2} \mathrm{P}$ Electrocatalyst for Hydrogen Evolution Reaction. J. Catal. 2015, 326, 92-99.

33. Friebel, D., et al., Identification of Highly Active Fe Sites in (Ni,Fe)OOH for Electrocatalytic Water Splitting. J. Am. Chem. Soc. 2015, 137, 1305-1313.

34. Burke, M. S.; Enman, L. J.; Batchellor, A. S.; Zou, S. H.; Boettcher, S. W., Oxygen Evolution Reaction Electrocatalysis on Transition Metal Oxides and (Oxy)Hydroxides: Activity Trends and Design Principles. Chem. Mater. 2015, 27, 7549-7558.

35. Chen, J. Y. C.; Dang, L. N.; Liang, H. F.; Bi, W. L.; Gerken, J. B.; Jin, S.; Alp, E. E.; Stahl, S. S., Operando Analysis of Nife and Fe Oxyhydroxide Electrocatalysts for Water Oxidation: Detection of $\mathrm{Fe}^{4+}$ by Mossbauer Spectroscopy. J. Am. Chem. Soc. 2015, 137, 15090-15093.

36. Trotochaud, L.; Young, S. L.; Ranney, J. K.; Boettcher, S. W., Nickel-Iron Oxyhydroxide Oxygen-Evolution Electrocatalysts: The Role of Intentional and Incidental Iron Incorporation. J. Am. Chem. Soc. 2014, 136, 6744-6753. 